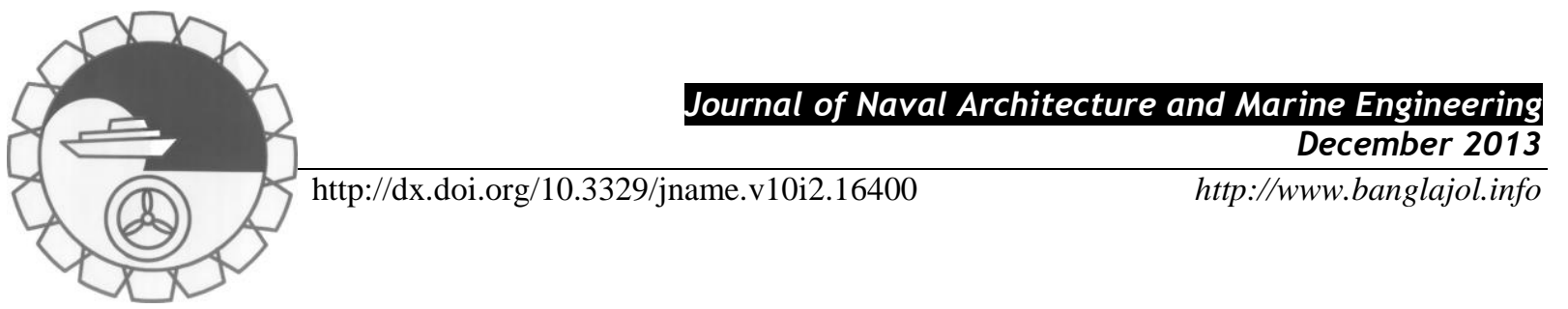

\title{
MHD BOUNDARY LAYER FLOW ON HEAT AND MASS TRANSFER OVER A STRETCHING SHEET WITH SLIP EFFECT
}

\author{
B. Rushi Kumar
}

Fluid Dynamics Division, School of Advanced Sciences, VIT University, Vellore, T.N, INDIA - 632014 Email: rushibkumar@gmail.com

\begin{abstract}
:
The present paper investigates the effect of linear thermal stratification in stable stationary ambient fluid on steady MHD convective flow of a viscous incompressible electrically conducting fluid along a stretching sheet in the presence of mass transfer and magnetic effect. The governing equations of continuity, momentum, energy and species are transformed into ordinary differential equations using local similarity transformation. The resulting coupled non-linear ordinary differential equations are solved using Runge-Kutta fourth order method along with shooting technique. The velocity, temperature and concentration distributions are discussed numerically and presented through graphs. The numerical values of skin-friction coefficient, Nusselt number and Sherwood number at the plate are derived and discussed numerically for various values of physical parameters which are presented through tables.
\end{abstract}

Keywords: Boundary layer, stretching sheet, MHD, partial slip, heat and mass transfer.

$\begin{array}{cl}\text { NOMENCLATURE } \\ T_{w} & \text { Temperature of the hot fluid } \\ C_{w} & \text { species concentration at the plate } \\ K & \text { Slip parameter } \\ L & \text { Proportional constant of the velocity slip } \\ G r & \text { local temperature Grashof number } \\ G c & \text { local concentration Grashof number } \\ B_{0} & \text { magnetic induction } \\ Q_{0} & \text { volumetric rate of heat generation/absorption } \\ D_{m} & \text { mass diffusivity } \\ M & \text { magnetic parameter } \\ Q & \text { heat source/sink parameter } \\ S c & \text { Schmidt number } \\ \operatorname{Pr} & \text { Prandtl number } \\ T & \text { Temperature } \\ C & \text { Concentration } \\ C & \text { free stream concentration } \\ U_{\infty} & \text { free stream velocity } \\ h & \text { heat transfer coefficient }\end{array}$

$\begin{array}{cl}\text { Greek symbols } \\ u, v & \text { dimensionless velocity components } \\ g & \text { gravitational acceleration } \\ C_{f} & \text { local skin friction coefficient } \\ k & \text { Thermal conductivity coefficient } \\ \beta_{T} & \text { coefficient of thermal expansions } \\ \beta_{c} & \text { coefficient of concentration expansions } \\ \eta & \text { dimensionless similarity variable } \\ \lambda & \text { Concentration exponent } \\ f & \text { dimensionless stream function } \\ \theta & \text { dimensionless temperature of the fluid } \\ \phi & \text { dimensionless concentration of the fluid } \\ v & \text { kinematic viscosity } \\ \rho & \text { density of the fluid } \\ \sigma & \text { electrical conductivity } \\ \tau_{w} & \text { shearing stress } \\ \psi & \text { stream function } \\ \alpha & \text { thermal diffusivity } \\ \beta & \text { convective Parameter }\end{array}$

\section{Introduction}

The study of flow over a stretching sheet has generated much interest in recent years due to its important contribution especially in many engineering processes and industries. The applications in industries involved such as the aerodynamic extrusion of plastic sheets, glass-fiber production, and condensation process of metallic 
plate in a cooling bath and glass and also in polymer industries. Crane (1970) was the first who reported the analytical solution for the laminar boundary layer flow past a stretching sheet. After this pioneering work, the study of fluid flow over a stretching sheet has received wide attention among researchers. Gupta and Gupta (1977) added new dimension to the study with suction and injection. A similar work was done by Kumaran et al. (2010), who analyzed transition effect of boundary layer flow due to an imposed and withdrawal of magnetic field over a viscous flow past a stretching sheet. The first paper on non- Newtonian with stretching sheet in nanofluids was introduced by Hamad and Bashir (2009) considering the problem of two-dimensional laminar mixed convection flow of a power-law non-Newtonian nanofluid over a vertical stretching sheet. Later, Khan and Pop (2010) analyzed numerically the problem of laminar fluid flow past a stretching sheet in a nanofluid. The study of flow over a stretching sheet later continued by Arnold et al. (2010), who considered the viscoelastic fluid flow and heat transfer characteristics with the effects of viscous dissipation and internal heat generation or absorption. Besides that, a collection of papers mentioned above which studied the stretching flow problems apply the no-slip condition. On the other hand, in certain circumstance, partial slip may occur between the fluid and the moving surface. Emulsions, suspensions, foams and polymer solutions are the examples when the fluid is particulate which partial slip effect may take place (Yoshimura and Prudhomme (1988)). Wang (2002) has investigated the flow due to a stretching surface with partial slip. In recent years, investigations on the boundary layer flow problem with a convective surface boundary condition have gained much interest among researchers, since first introduced by Aziz (2009), who considered the thermal boundary layer flow over a flat plate in a uniform free stream with a convective surface boundary condition. Ishak (2010) obtained the similarity solutions for the steady laminar boundary layer flow over a permeable plate with a convective boundary condition. Makinde and Aziz (2011) investigated numerically the effect of a convective boundary condition on the two dimensional boundary layer flows past a stretching sheet in a nanofluid.

All the above investigations are restricted to MHD flow and mass transfer problems. Analysis of heat and mass transfer of a viscoelastic, electrically conducting fluid past a continuous stretching sheet was investigated by Kelly and Vajravelu (1999). Raju et al. (2011) studied the Hall-current effects on unsteady MHD flow between stretching sheet and an oscillating porous upper parallel plate with constant suction. Mukhopadhyay and Gorla (2012) analyzed unsteady MHD boundary layer flow of an upper convected Maxwell fluid past a stretching sheet with first order constructive/destructive chemical reaction. Kishore et al. (2010) investigated the effects of heat transfer and viscous dissipation on MHD free convection flow past an exponentially accelerated vertical plate with variable temperature. Reddy et al. analyzed (2008) the effect of aligned Magnetic field on unsteady flow between a stretching sheet and oscillating porous plate with constant suction. Pop and Na (1998) solved the boundary layer flow over a permeable stretching sheet in the presence of a magnetic field. Reddy and Reddy (2011) analyzed the thermal radiation effects on hydromagnetic flow due to an exponentially stretching sheet. Raptis et al. (2004) studied the effect of thermal radiation on the magneto hydrodynamic flow of a viscous fluid past a semi-infinite stationary plate. Aliakbar et al. (2009) investigated the influence of thermal radiation on MHD flow of maxwellian fluids above stretching sheets. A few years later, Wang (2009) continued the study on viscous flow due to a stretching sheet with suction and injection. Besides that, slip magnetohydrodynamic viscous flow over a permeable shrinking sheet was analyzed analytically by Fang et al. (2010). Siddiqui et al. (2011) have solved analytically the two boundary value problems for MHD flow of an Oldroyd-B fluid between two infinite parallel plates with the effect of partial slip. Recently Bakar et al. (2012) analyzed boundary layer flow over a stretching sheet with a convective boundary condition and slip effect. Very recently Jat et al. (2013) studied MHD flow and heat transfer over an exponentially stretching sheet with viscous dissipation and radiation effects.

The object of the present paper is to analyze steady two-dimensional laminar boundary layer flow of a viscous, incompressible, electrically conducting fluid past a stretching sheet with slip effect. The governing boundary layer equations have been transformed to a two-point boundary value problem in similarity variables and the resultant problem is solved numerically using the Runge-Kutta method with shooting technique. The effects of various governing parameters on the fluid velocity, temperature, concentration, skin-friction coefficient, Nusselt number and Sherwood number are shown in figures and tables and analyzed in detail.

\section{Mathematical Formulation}

A steady two-dimensional laminar boundary layer flow of a viscous, incompressible, electrically conducting fluid past a stretching sheet is considered. A uniform surface temperature $T_{w}$ immersed in a quiescent viscous fluid. A temperature dependent heat source (or sink) is assumed to be present in the flow. It is assumed that the sheet is stretched with linear velocity $u_{w}=a x$, where a is a positive constant. A uniform magnetic field is 
applied in the direction perpendicular to the plate. The transverse applied magnetic field and magnetic Reynolds number are assumed to be very small, so that the induced magnetic field is negligible. It is assumed that the concentration $C_{w}$ of the diffusing species in the binary mixture is very less in comparison to the other chemical species, which are present, and hence the Joule and viscous dissipation effects are negligible. It is also assumed that there is no chemical reaction between the diffusing species and the fluid. Then, under the above assumptions, in the absence of an input electric field, the governing boundary layer equations with Boussinesq's approximation are:

Continuity equation

$$
\frac{\partial u}{\partial x}+\frac{\partial v}{\partial y}=0
$$

Momentum equation

$u \frac{\partial u}{\partial x}+v \frac{\partial u}{\partial y}=v \frac{\partial^{2} u}{\partial y^{2}}-\frac{\sigma B_{0}^{2}}{\rho} u+g \beta_{T}\left(T-T_{\infty}\right)+g \beta_{c}\left(C-C_{\infty}\right)$

Energy equation

$\rho c_{p}\left(u \frac{\partial T}{\partial x}+v \frac{\partial T}{\partial y}\right)=k \frac{\partial^{2} T}{\partial y^{2}}$

Species equation

$u \frac{\partial C}{\partial x}+v \frac{\partial C}{\partial y}=D_{m} \frac{\partial^{2} C}{\partial y^{2}}$

The boundary conditions for the velocity, temperature and concentration fields are

$u=u_{w}+L \frac{\partial u}{\partial y}, v=0,-\kappa \frac{\partial T}{\partial y}=h\left[T-T_{w}\right], C_{w}=A x^{\lambda}+C_{\infty}$ at $y=0$

$u=0, T=T_{\infty}, C=C_{\infty}$ as $y=\infty$

The mass concentration equation (2.1) is satisfied by the Cauchy-Riemann equations

$u=\frac{\partial \psi}{\partial y}, v=-\frac{\partial \psi}{\partial x}$

where $\psi(x, y)$ is the stream function.

To transform equations (2.2) - (2.4) into a set of ordinary differential equations, the following similarity transformations and dimensionless variables are introduced.

$$
\begin{aligned}
& \eta=y \sqrt{\frac{a}{v}}, \psi=\sqrt{v a} x f(\eta) \theta(\eta)=\frac{T-T_{\infty}}{T_{w}-T_{\infty}}, \phi(\eta)=\frac{C-C_{\infty}}{C_{w}-C_{\infty}}, M=\frac{\sigma B_{0}^{2} x}{\rho U_{\infty}}, G r=\frac{g \beta_{T}\left(T_{w}-T_{\infty}\right) x}{U_{\infty}^{2}} \\
& G c=\frac{g \beta_{c}\left(C_{w}-C_{\infty}\right) x}{U_{\infty}^{2}}, \quad K=L \sqrt{\frac{v}{U_{\infty}}}, \beta=\frac{c}{k} \sqrt{\frac{v}{U_{\infty}}}, \operatorname{Pr}=\frac{v}{\alpha}, S c=\frac{v}{D_{m}}
\end{aligned}
$$

In view of Equations (2.6) and (2.7), Equations (2.2) to (2.4) transform into

$$
\begin{aligned}
& f^{\prime \prime \prime}+\frac{1}{2} f f^{\prime \prime}-M f^{\prime}+G r \theta+G c \phi=0 \\
& \theta^{\prime \prime}+\frac{1}{2} \operatorname{Pr} f \theta^{\prime}=0 \\
& \phi^{\prime \prime}+\frac{1}{2} S c f \phi^{\prime}=0
\end{aligned}
$$

The corresponding boundary conditions are

$$
\begin{aligned}
& f=0, f^{\prime}=1+K f^{\prime \prime}, \theta^{\prime}=\beta[\theta-1], \phi=1 \quad \text { at } \quad y=0 \\
& f^{\prime}=\theta=\phi=0 \quad \text { as } \quad y \rightarrow \infty
\end{aligned}
$$

where the prime symbol represents the derivative with respect to $\eta$. 
It is noteworthy that the local parameters $\beta, M, G r$ and $G c$ in Equations (8) - (9) are functions of x. However, in order to have a similarity solution all the parameters $\beta, M, G r$ and $G c$ must be constant and we therefore assume

$h=c x^{-\frac{1}{2}}, \sigma=a x^{-1}, \beta_{T}=b x^{-1}$ and $\beta_{c}=d x^{-1}$

where $\mathrm{a}, \mathrm{b}, \mathrm{c}, \mathrm{d}$ are constants

Other physical quantities of interest for the problem of this type are the skin friction parameter $C_{f}=2(\mathrm{Re})^{-\frac{1}{2}} f^{\prime \prime}(0)$, the plate surface temperature $\theta(0)$, Nusselt number $N u=-(\operatorname{Re})^{\frac{1}{2}} \theta^{\prime}(0)$ and the Sherwood number $S h=-(\operatorname{Re})^{\frac{1}{2}} \phi^{\prime}(0)$ (where $\operatorname{Re}=\frac{U t}{v}$ is the Reynolds number). For local similarity case, integration over the entire plate is necessary to obtain the total skin friction, total heat and mass transfer rates.

\section{Method of Solution}

The set of coupled non-linear governing boundary layer equations (8)-(10) together with the boundary conditions (11\&12) are solved numerically by using Runge-Kutta fourth order technique along with shooting method. First of all, higher order non-linear differential Equations (8)-(10) are converted into simultaneous linear differential equations of first order and they are further transformed into initial value problem by applying the shooting technique (Alam et al. (2006)). In a shooting method, the missing (unspecified) initial condition at the initial point of the interval is assumed, and the differential equation is then integrated numerically as an initial value problem to the terminal point. The accuracy of the assumed missing initial condition is then checked by comparing the calculated value of the dependent variable at the terminal point with its given value there. If a difference exists, another value of the missing initial condition must be assumed and the process is repeated. This process is continued until the agreement between the calculated and the given condition at the terminal point is within the specified degree of accuracy. For this type of iterative approach, one naturally inquires whether or not there is a systematic way of finding each succeeding (assumed) value of the missing initial condition.

The resultant initial value problem is solved by employing Runge-Kutta fourth order technique. The step size $\Delta \eta=0.05$ is used to obtain the numerical solution with decimal place accuracy as the criterion of convergence. From the process of numerical computation, the skin-friction coefficient, the Nusselt number and the Sherwood number, which are respectively proportional to $f^{\prime \prime}(0),-\theta^{\prime}(0)$ and $-\varphi^{\prime}(0)$ are also sorted out and their numerical values are presented in a tabular form.

\section{Results and Discussion}

The governing equations (8) - (10) subject to the boundary conditions (11) are integrated as described in Section 3. Numerical results are reported in the Tables 1-2. The Prandtl number is taken to be $\operatorname{Pr}=0.71$ which corresponds to air, the value of Schmidt number (Sc) were chosen to be $\mathrm{Sc}=0.24,0.62,0.78,2.62$, representing diffusing chemical species of most common interest in air like $\mathrm{H}_{2}, \mathrm{H}_{2} \mathrm{O}, \mathrm{NH}_{3}$ and Propel Benzene respectively.

The effects of various parameters on velocity profiles in the boundary layer are depicted in Figs. 1-6. In Fig. 1 the effect of increasing the magnetic field strength on the momentum boundary layer thickness is illustrated. It is now a well established fact that the magnetic field presents a damping effect on the velocity field by creating drag force that opposes the fluid motion, causing the velocity to decease. Fig. 2 shows the variation of the velocity boundary-layer with the convective parameter $(\beta)$. It is noticed that the velocity boundary layer thickness increases with an increase in the convective parameter. Fig. 3 and 4 illustrate the effect of the thermal and solutal Grashof number $(G r$ and $G c$ ) on the velocity field. The thermal Grashof number signifies the relative effect of the thermal buoyancy force to the viscous hydrodynamic force. The flow is accelerated due to the enhancement in buoyancy force corresponding to an increase in the thermal Grashof number i.e. free convection effects. It is noticed that the thermal Grashof number $(G r)$ influences the velocity field almost in the boundary layer when compared to far away from the sheet. It is seen that as the thermal Grashof number $(G r)$ increases, the velocity field increases. The solutal Grashof number $(G c)$ defines the ratio of the species buoyancy force to the viscous hydrodynamic force. It is noticed that the velocity increases with increasing values of the solutal 
Grashof number. Further as the solutal Grashof number $(G c)$ increases, the velocity field near the boundary layer increases.

Fig. 5 illustrates the effect of the Schmidt number $(S c)$ on the velocity. The Schmidt number $(S c)$ embodies the ratio of the momentum diffusivity to the mass (species) diffusivity. It physically relates the relative thickness of the hydrodynamic boundary layer and mass-transfer (concentration) boundary layer. It is noticed that as Schmidt number $(S c)$ increases the velocity field decreases. Fig. 6 shows the variation of the velocity boundary-layer with the slip parameter $(K)$. It is found that the velocity boundary layer thickness decreases with an increase in the slip parameter.

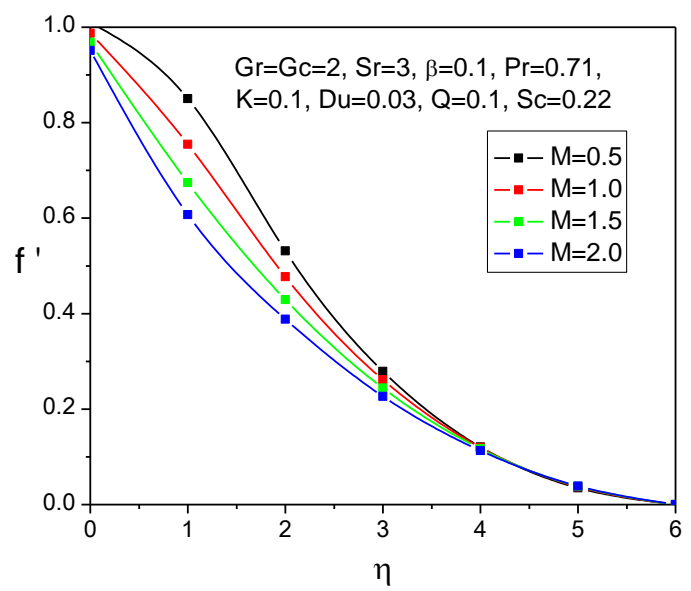

Fig.1: Velocity profiles for various values of $\mathrm{M}$

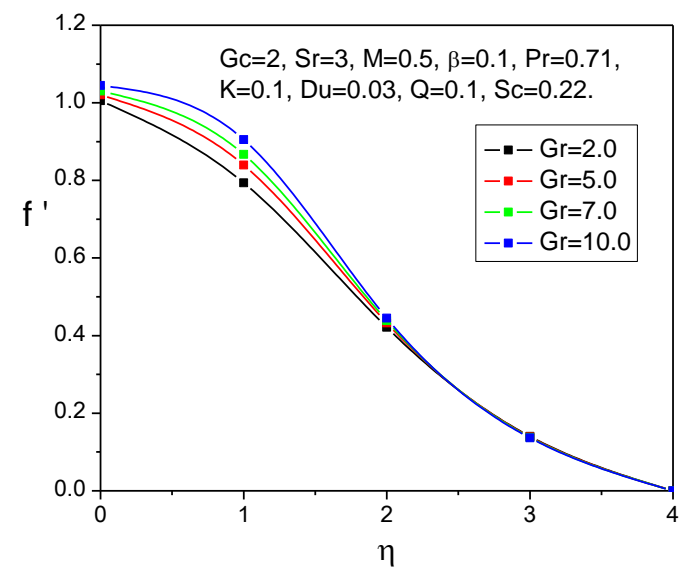

Fig. 3: Velocity profiles for various values of $\mathrm{Gr}$

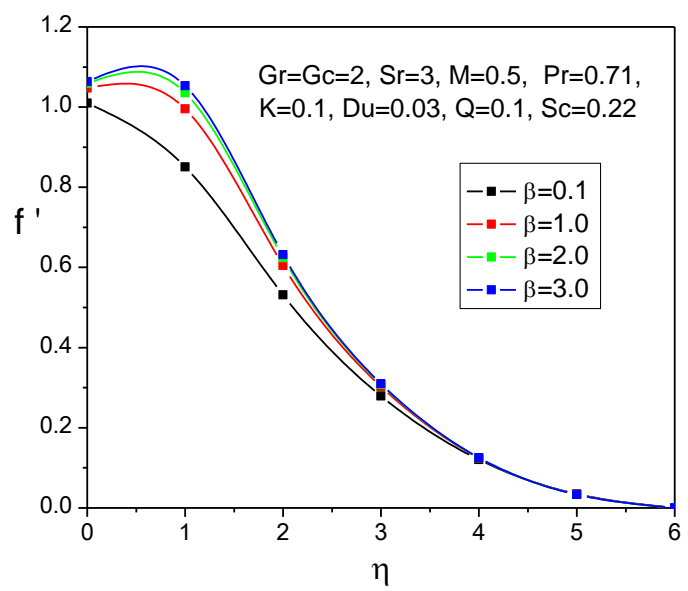

Fig. 2: Velocity profiles for various values of $\beta$

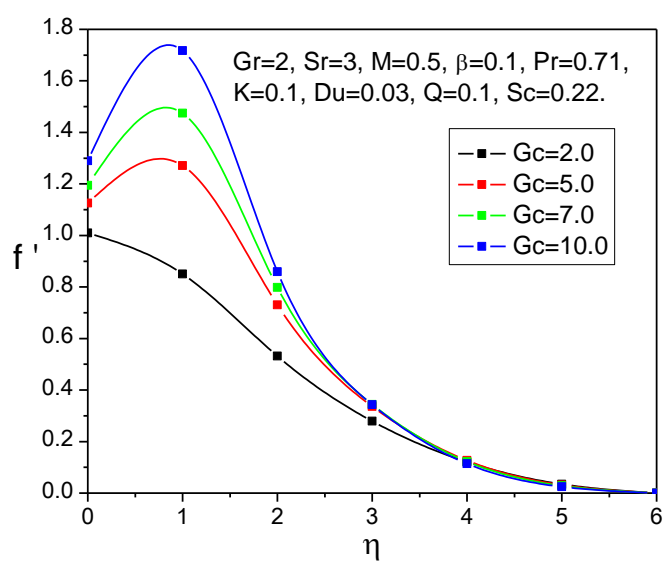

Fig. 4: Velocity profiles for various values of $\mathrm{Gc}$

As per the boundary conditions of the flow field under consideration, the fluid temperature attains its maximum value at the surface and decreases exponentially to the free stream zero value away from the plate. This is observed in Figs. 7-13. The effect of the magnetic parameter $(M)$ on the temperature is illustrated in Fig.7. It is observed that as the magnetic parameter increases, the temperature increases. Fig.8 illustrates the effect of the convective parameter $(\beta)$ on the temperature. It is noticed that as convective parameter increases, the temperature increases. From Figs. 9 and 10, it is observed that the boundary layer thickness decreases with an increase in the thermal and solutal Grashof number $(G r$ and $G c)$.

Fig. 11 illustrates the effect of Schmidt number $(S c)$ on the temperature. It is noticed that as the Schmidt number $(S c)$ increases an increasing trend in the temperature field is noticed. Much of significant contribution of Schmidt number $(S c)$ is noticed as we move far away from the plate. The effect of Prandtl number $(P r)$ on the temperature field is illustrated in Fig.12. As the Prandtl number $(P r)$ increases the thermal boundary layer is 
found to be decreasing. The effect of slip parameter $(\mathrm{K})$ on the temperature field is illustrated in Fig.13. As the slip parameter $(\mathrm{K})$ increases the thermal boundary layer is found to be increasing.

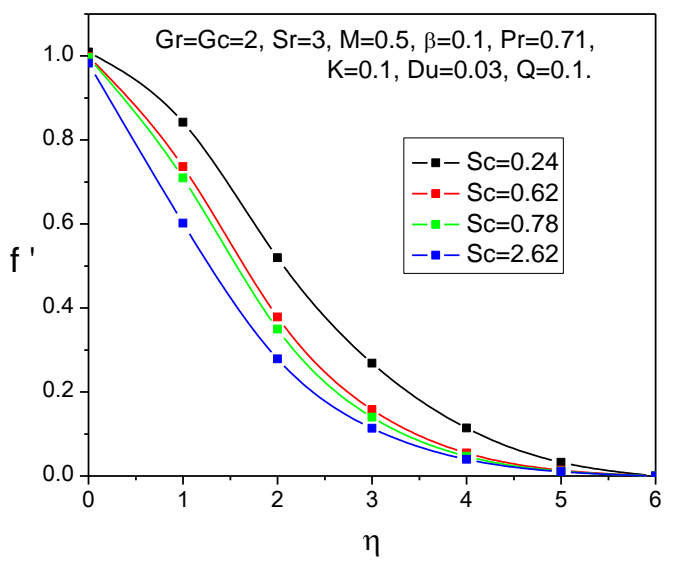

Fig. 5: Velocity profiles for various values of Sc

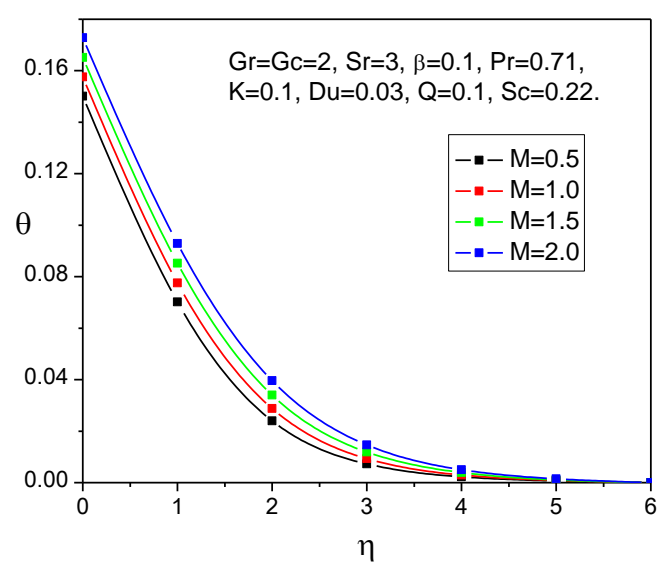

Fig. 7: Temperature profiles for different $\mathrm{M}$

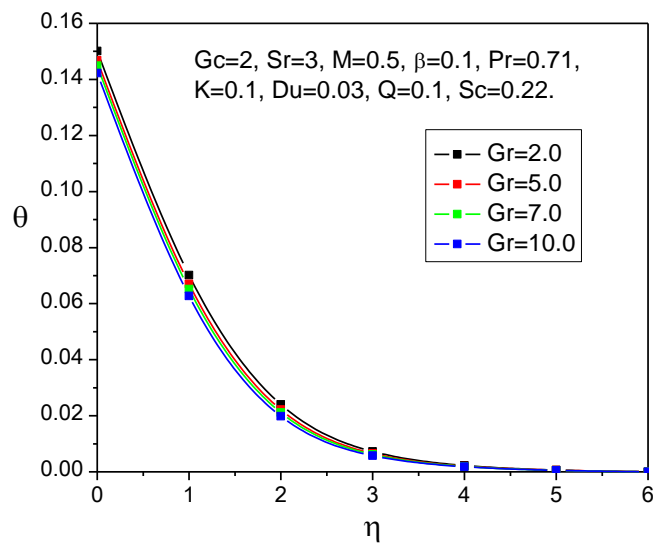

Fig. 9: Temperature profiles for different $\mathrm{Gr}$

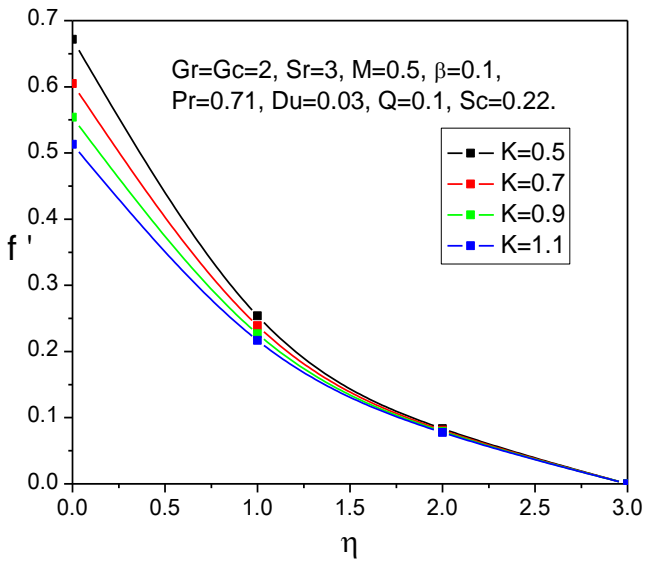

Fig. 6: Velocity profiles for various values of $\mathrm{K}$

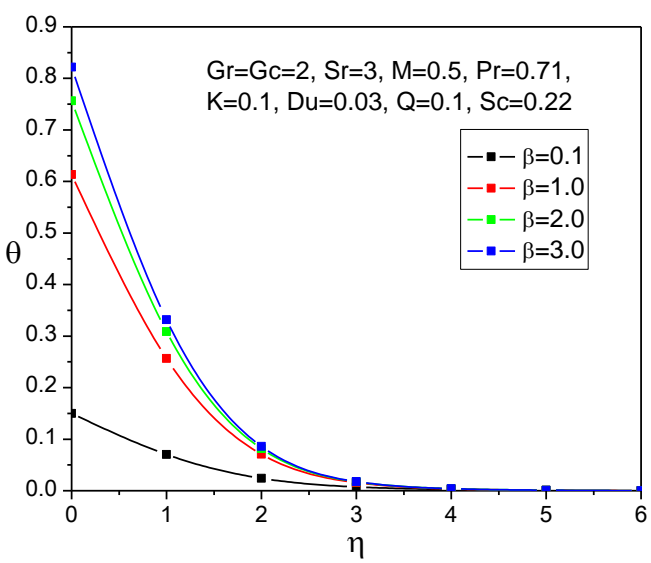

Fig. 8: Temperature profiles for different $\beta$

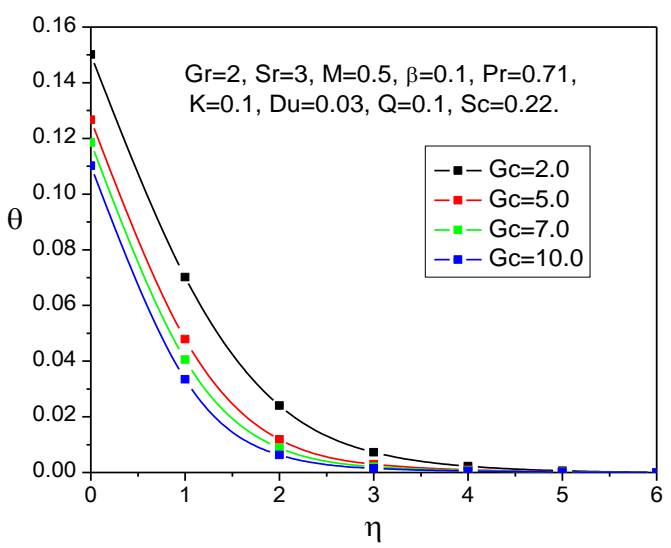

Fig. 10: Temperature profiles for different Gc 


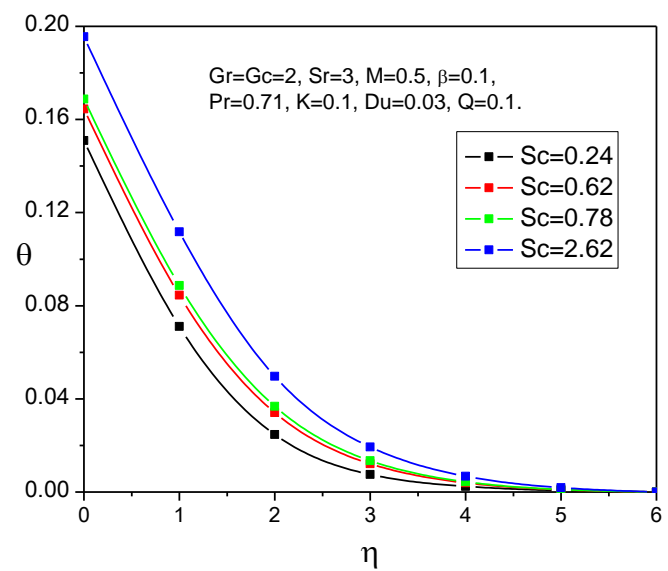

Fig. 11: Temperature profiles for different $\mathrm{S}$

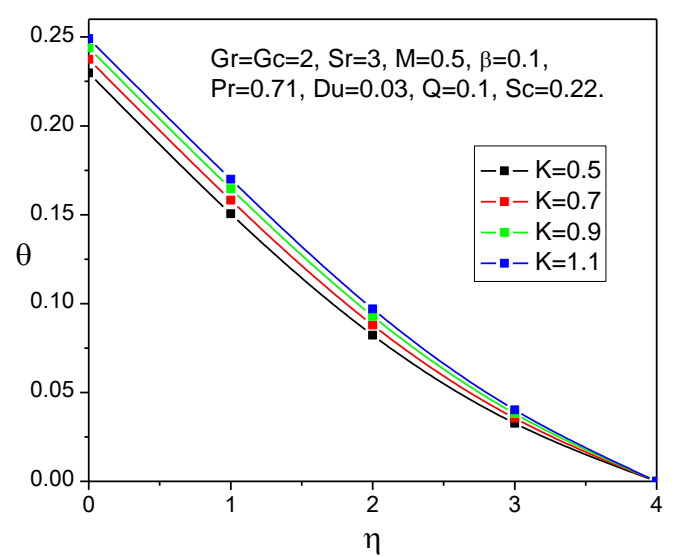

Fig. 13: Temperature profiles for different $\mathrm{K}$

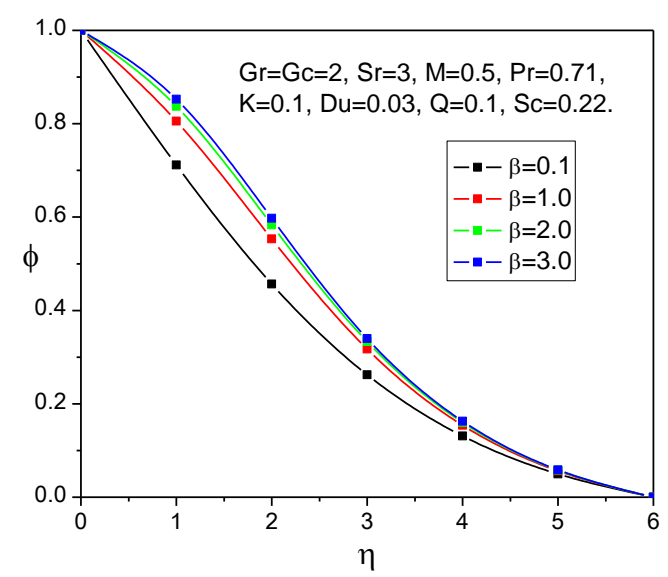

Fig. 15: Concentration profiles for different $\beta$

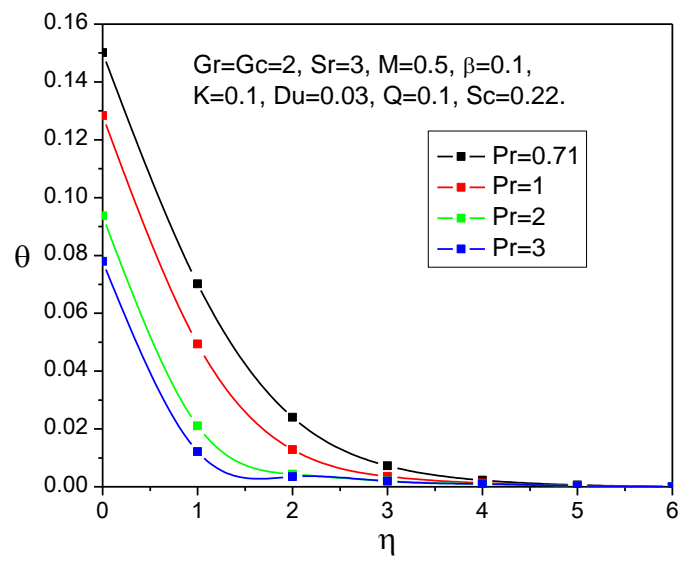

Fig. 12: Temperature profiles for different $\mathrm{Pr}$

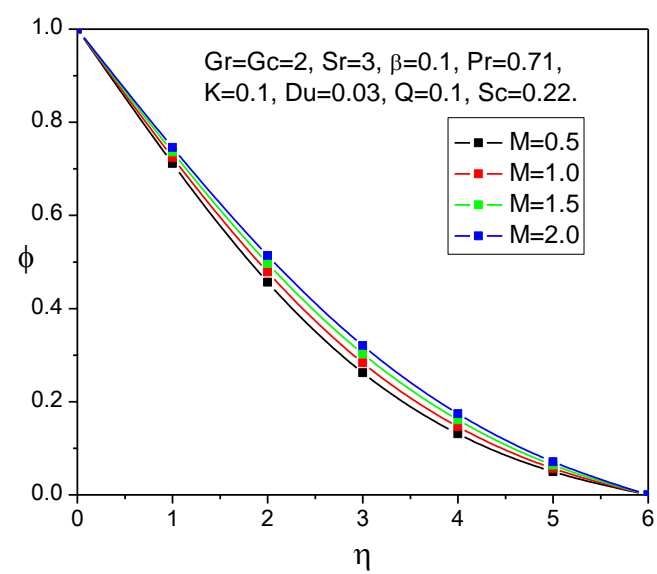

Fig. 14: Concentration profiles for different $\mathrm{M}$

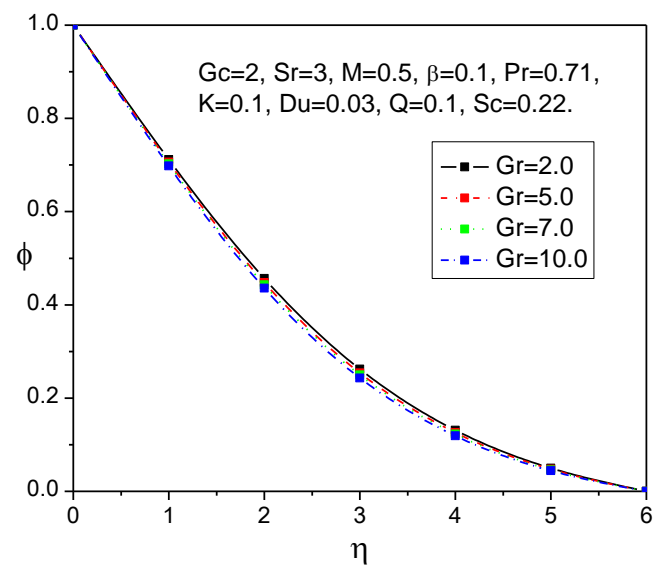

Fig. 16: Concentration profiles for different $\mathrm{Gr}$

Figs. 14-18 depict chemical species concentration against span wise coordinate $\eta$ for varying values physical parameters in the boundary layer. The species concentration is highest at the plate surface and decrease to zero far away from the plate satisfying the boundary condition. The effect of magnetic parameter $(M)$ on the 
concentration field is illustrated in Fig.14. As the magnetic parameter increases the concentration is found to be increasing. However, as we move away from the boundary layer, the effect is not significant. The influence of the convective parameter $(\beta)$ on the concentration field is shown in Fig. 15. It is noticed that the concentration increases monotonically with the increase of the Convetive parameter. The effect of buoyancy parameter $(\mathrm{Gr}$ and $G c$ ) on the concentration field is illustrated Figs. 16 and 17. It is noticed that the concentration boundary layer thickness decreases with an increase in the thermal Grashof numbers $(G r)$. Fig. 18 illustrates the effect of Schmidt number $(S c)$ on the concentration. It is noticed that as the Schmidt number $(S c)$ increases, there is a decreasing trend in the concentration field. Not much of significant contribution of Schmidt number $(S c)$ is noticed as we move far away from the plate.

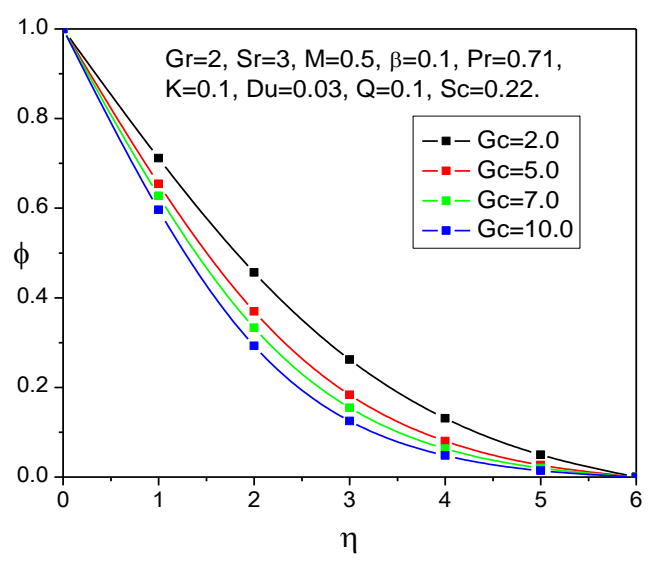

Fig. 17: Concentration profiles for different Gc

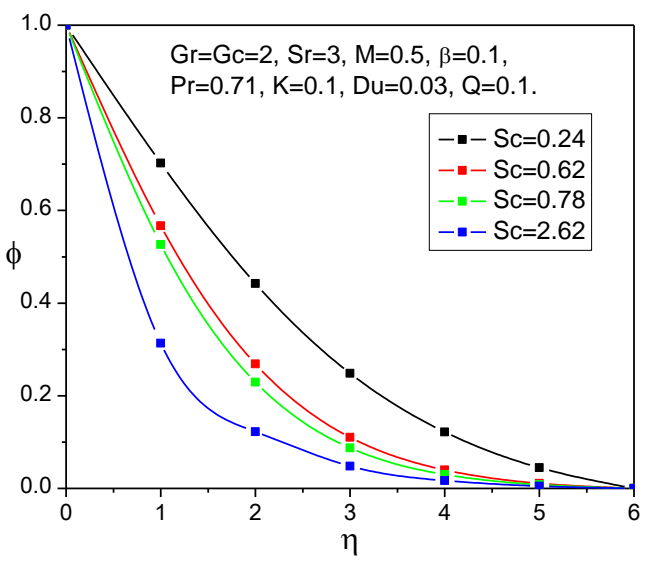

Fig. 18: Concentration profiles for different Sc

Table 1. Variation of $f^{\prime \prime}(0),-\theta^{\prime}(0)$ and $-\varphi^{\prime}(0)$ at the plate with $G r, G c, S c, \beta, P r, M$ and $K$.

\begin{tabular}{|c|c|c|c|c|c|c|c|c|c|}
\hline $\mathbf{G r}$ & $\mathbf{G c}$ & $\mathbf{S c}$ & $\boldsymbol{\beta}$ & $\mathbf{P r}$ & $\mathbf{M}$ & $\mathbf{K}$ & $f^{\prime \prime}(0)$ & $-\theta^{\prime}(0)$ & $-\phi^{\prime}(0)$ \\
\hline 0.1 & 0.1 & 0.22 & 0.1 & 0.71 & 0.5 & 0.5 & -0.0516566 & 0.015981 & 0.140164 \\
0.5 & 0.1 & 0.22 & 0.1 & 0.71 & 0.5 & 0.5 & -00610624 & 0.0143284 & 0.137955 \\
1.0 & 0.1 & 0.22 & 0.1 & 0.71 & 0.5 & 0.5 & -0.0697672 & 0.0127539 & 0.135598 \\
0.1 & 0.5 & 0.22 & 0.1 & 0.71 & 0.5 & 0.5 & -0.125531 & 0.00804744 & 0.126196 \\
0.1 & 1.0 & 0.22 & 0.1 & 0.71 & 0.5 & 0.5 & -0.176409 & 0.00425332 & 0.113364 \\
0.1 & 0.1 & 0.62 & 0.1 & 0.71 & 0.5 & 0.5 & -0.0416299 & 0.0168136 & 0.0908397 \\
0.1 & 0.1 & 0.78 & 0.1 & 0.71 & 0.5 & 0.5 & -0.0385498 & 0.0170889 & 0.0741271 \\
0.1 & 0.1 & 0.22 & 0.5 & 0.71 & 0.5 & 0.5 & -0.0561319 & 0.0419272 & 0.139149 \\
0.1 & 0.1 & 0.22 & 1.0 & 0.71 & 0.5 & 0.5 & -0.0579597 & 0.0527984 & 0.138717 \\
0.1 & 0.1 & 0.22 & 0.1 & 3.0 & 0.5 & 0.5 & -0.0488748 & 0.00011576 & 0.140675 \\
0.1 & 0.1 & 0.22 & 0.1 & 4.0 & 0.5 & 0.5 & -0.0488316 & 0.000012892 & 0.140708 \\
0.1 & 0.1 & 0.22 & 0.1 & 0.71 & 1.0 & 0.5 & -0.0347956 & 0.0205813 & 0.145219 \\
0.1 & 0.1 & 0.22 & 0.1 & 0.71 & 1.5 & 0.5 & -0.0252397 & 0.0244575 & 0.148636 \\
0.1 & 0.1 & 0.22 & 0.1 & 0.71 & 0.5 & 1.0 & -0.0537829 & 0.0193168 & 0.143749 \\
0.1 & 0.1 & 0.22 & 0.1 & 0.71 & 0.5 & 1.5 & -0.0548579 & 0.0216358 & 0.14591 \\
\hline
\end{tabular}

From Table 1, it is observed that the local skin-friction, Nusselt number and Sherwood number coefficient decrease with an increase in the buoyancy forces. As the magnetic parameter increase, the skin-friction, Nusselt number and Sherwood number increases. As the Schmidt number increase, both the skin-friction and Nusselt 
number increases, whereas the Sherwood number decreases. It is found that the local skin-friction coefficient and Sherwood number increase, where as Nusselt number decreases with an increase in the Prandtl number. It is observed that the Nusselt number and Sherwood number increase, where as skin-friction coefficient increases with an increase the slip parameter. It is noticed that the skin-friction and Sherwood number decrease, where as Nusselt number increases with an increase in the convective parameter.

\section{Conclusions}

The present paper analyzes the steady laminar boundary layer flow on heat and mass transfer over a stretching sheet with partial slip under a convective surface boundary condition by taking mass transfer and magnetic effect into account. The governing equations are approximated to a system of non-linear ordinary differential equations by similarity transformation. Numerical calculations are carried out for various values of the dimensionless parameters of the problem. The results are presented graphically and the conclusion is drawn that the flow field and other quantities of physical interest are significantly influenced by these parameters. The results for the prescribed skin friction, local heat and mass transfer rates at the plate are presented and discussed. It is observed that the local skin-friction, Nusselt number and Sherwood number coefficient decreases with an increase in the buoyancy forces. As the Magnetic parameter increases, the skin-friction, Nusselt number and Sherwood number increase. As the Schmidt number increases, both the skin-friction and Nusselt number increase, whereas the Sherwood number decreases.

\section{References}

Aliakbar, V., Alizadeh-pahlawan, A. and Sadeghy, K. (2009): The Influence of Thermal Radiation on MHD Flow of Maxwellian Fluids above Stretching Sheets, Commun. Nonlinear Science Numerical Simulation, Volume 14, Issue 3, pp 779-794 http:/dx.doi.org/10.1016/j.cnsns.2007.12.003

Arnold, J. C., Asir, A. A., Somasundaram, S. and Christopher, T. (2010): Heat Transfer in a Viscoelastic Boundary Layer Flow Over a Stretching Sheet, Int. J. Heat Mass Transfer, Vol.53, pp.1112-1118. http:/dx.doi.org/10.1016/j.ijheatmasstransfer.2009.10.046

Aziz, A., (2009): A similarity Solution for Laminar Thermal Boundary Layer Over a Flat Plate with a Convective Surface Boundary Condition, Commun. Nonlinear Sci. Numer. Simulat, Vol.14, pp.1064-1068. http:/dx.doi.org/10.1016/j.cnsns.2008.05.003

Bakar, N. A. A., Zami, W, M. K. A. W., Hamid, R. A., Bidin, B. and Ishak, I. (2012): Boundary Layer Flow over a Stretching Sheet with a Convective Boundary Condition and Slip Effect, World Applied Sciences Journal $17,49-53$.

Crane, L. (1970): Flow Past a Stretching Plate, Z. Angew. Math. Phys., Vol.21, pp.645-647. http:/dx.doi.org/10.1007/BF01587695

Gupta, P.S. and Gupta, A.S. (1977): Heat and Mass Transfer on a Stretching Sheet with Suction or Blowing, Can. J. Chem. Eng., Vol.55, pp.744-746. http:/dx.doi.org/10.1002/cjce.5450550619

Hamad, M.A.A. and Bashir, M.A. (2009): Boundary- Layer Flow and Heat Transfer of a Power Law NonNewtonian Nanofluid over a Vertical Stretching Sheet, World Applied Sciences Journal 7 (Special Issue for Applied Math), pp: 172-178.

Ishak, A. (2010): Similarity solutions for flow and heat transfer over a permeable surface with convective boundary condition. Appl. Math. Computation, Vol.217, pp.837-842. http:/dx.doi.org/10.1016/j.amc.2010.06.026

Jain, M. K., Iyengar, S. R. K. and Jain, R. K. (1985): Numerical Methods for Scientific and Engineering Computation, Wiley Eastern Ltd., New Delhi, India. http:/dx.doi.org/10.1002/zamm.19860661224

Jat, R.N. and Chand, C. (2013): MHD Flow and Heat Transfer over an Exponentially Stretching Sheet with Viscous Dissipation and Radiation Effects, Applied Mathematical Sciences, Vol. 7, no. 4, 167 - 180.

Kelly, D., Vajravelu, K. and Andrews, L.(1999): Analysis of Heat and Mass Transfer of a Viscoelastic, Electrically Conducting Fluid past a Continuous Stretching Sheet, Nonlinear Analysis ,Vol. 36, No. 6, pp. 767 784. http:/dx.doi.org/10.1016/S0362-546X(98)00128-X

Khan, W.A. and Pop, I. (2010): Boundary-layer Flow of a Nanofluid Past a Stretching Sheet, Int. J Heat Mass Transfer, Vol.53, pp.2477-2483. http:/dx.doi.org/10.1016/j.ijheatmasstransfer.2010.01.032 
Kishore, P.M., Rajesh.V. and Varma, S.V.K. (2010): Effects of Heat Transfer and Viscous Dissipation on MHD Free Convection Flow Past an Exponentially Accelerated Vertical Plate with Variable Temperature, Journal of Naval Architecture and Marine Engineering, 7, 101-110. http:/dx.doi.org/10.3329/jname.v7i2.4370

Kumaran, V., Kumar, A.V. and Pop, I. (2010): Transition of MHD Boundary Layer Flow Past a Stretching Sheet, Commun Nonlinear Sci Numer Simulat., Vol.15, pp.300-311. http:/dx.doi.org/10.1016/j.cnsns.2009.03.027

Makinde, O. D. and Aziz, A. (2011): Boundary Layer Flow of a Nanofluid Past a Stretching Sheet with Convective Boundary Condition, Int. J. Therm. Sci., Vol. 50, pp.1326-1332. http:/dx.doi.org/10.1016/j.ijthermalsci.2011.02.019

Mukhopadhyay, S., Gorla, R.S.R.(2012): Unsteady MHD Boundary Layer Flow of an Upper Convected Maxwell Fluid Past a Stretching Sheet with First Order Cconstructive/Destructive Chemical Reaction, Journal of Naval Architecture and Marine Engineering, 9, 123-133. http:/dx.doi.org/10.3329/jname.v9i2.12541

Pop, I. and Na, T.Y. (1998): A Note on MHD Flow Over a Stretching Permeable Surface, Mech. Res. Commun, Vol.25 (3), pp.263-269.

Raju, M.C., Reddy, N. A. and Varma, S.V.K. (2011): Hall-current Effects on Unsteady MHD Flow between Stretching Sheet and an Oscillating Porous Upper Parallel Plate with Constant Suction, Thermal science, Vol. 15, No.2, pp.45-48. http:/dx.doi.org/10.2298/TSCI1102527C

Raptis, A., Perdikis, C. and Takhar, H.S. (2004): Effects of Thermal Radiation on MHD Flow, Applied Mathematics and Computation, Volume 153, Issue 3, pp 645-649 http:/dx.doi.org/10.1016/S0096$\underline{3003(03) 00657-X}$

Reddy P. B. A. and Reddy N. B. (2011): Thermal Radiation Effects on Hydromagnetic Flow Due to an Exponentially Stretching Sheet, International Journal of Applied Mathematics and Computation, Volume 3(4), pp. 300-306.

Reddy, N. P., Raju, M.C. and Varma, S.V.K. (2008): Effect of Aligned Magnetic Field on Unsteady Flow between a Stretching Sheet and Oscillating Porous Plate with Constant Suction, International Review of Pure and Applied Mathematics, Vol.4, No.2, pp.211-218.

Siddiqui, A.M., Haroon, T. , Zahid, M. and Shahzad, A. (2011): Effect of Slip Condition on Unsteady Flows of an Oldroyd-B Fluid between Parallel Plates, World Applied Sciences Journal, Vol. 13 (11), pp.2282-2287.

Takhar, H.S., Gorla, R.S.R. and Soundalgekar, V.M. (1996): Radiation Efects on MHD Free Convection Flow of a Gas Past a Semi-infinite Vertical Plate, Internat. J. Numer. Methods Heat Fluid Flow, Vol.6(2), pp.77-83. http:/dx.doi.org/10.1108/09615539610113118

Tie-Gang, F., Ji, Z. and Shan-Shan, Y(2010): Slip Magnetohydrodynamic Viscous Flow over a Permeable Shrinking Sheet, Chin. Phys. Lett. Vol. 27, No. 12 124702 http:/dx.doi.org/10.1088/0256-307X/27/12/124702

Wang, C.Y. (2002): Flow due to a Stretching Boundary with Partial Slip -an Exact Solution of the NavierStokes Equations, Chem. Eng. Sci, Vol.57, pp.3745-3747.

Wang, C.Y. (2009): Analysis of Viscous Flow due to a Stretching Sheet with Surface Sip and Suction, Nonlinear Anal Real World Appl., Vol.10 (1), pp.375-380. http:/dx.doi.org/10.1016/j.nonrwa.2007.09.013

Yoshimura, A. and Prudhomme, R.K. (1988): Wall Slip Corrections for Couette and Parallel Disc Viscometers, J. Rheol., Vol.32, pp.53-67. http:/dx.doi.org/10.1122/1.549963 